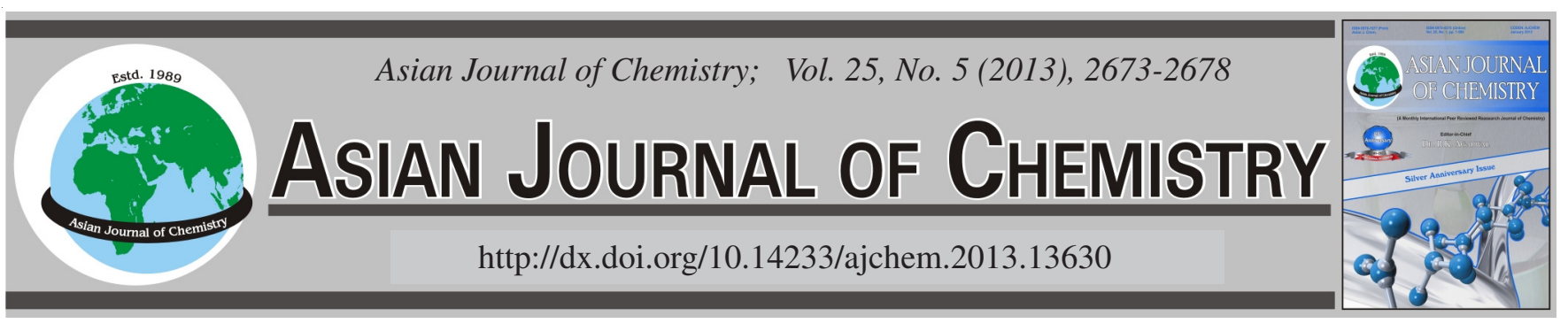

\title{
Optimization Design for Determination of Polycyclic Aromatic Hydrocarbons in Water Samples
}

\author{
W. $\mathrm{CHEN}^{1, \dagger}$, A.D. SuN ${ }^{1,2, * \dagger}$ and Q.C. XU ${ }^{2}$
}

${ }^{1}$ College of Environment, Hohai University, 1 Xikang Road, Nanjing 210098, P.R. China

${ }^{2}$ Shandong Provincial Key Laboratory of Soil Conversation and Environmental Protection, Linyi University, Linyi 276005, P.R. China

$\dagger$ The first two authors contributed equally to this paper.

*Corresponding author: Tel/Fax: + 86539 8766720; E-mail: sunaide@lyu.edu.cn

(Received: 20 February 2012;

Accepted: 19 November 2012)

AJC-12426

A response surface optimized method was proposed for the analysis of polycyclic aromatic hydrocarbons in drinking water using |
dispersive liquid phase microextraction and gas chromatography mass spectrometry. Methanol was selected as the dispersive solvent and
perchloroethylene as the extraction solvent. The volume of the extraction solvent, the volume of dispersive solvent and the solution $\mathrm{pH}$
were all important parameters. Their reproducibility was investigated under the optimized conditions. The relative standard deviations |
ranged from $9.0-11.3 \%$. The limits of detection, based on a signal-to-noise ratio of three, ranged from $0.52-1.67 \mathrm{ng} / \mathrm{L}$, lower than that
established by the Environmental Protection Agency.

Key Words: Dispersive liquid phase microextraction, Drinking water, Polycyclic aromatic hydrocarbons, Response surface method.

\section{INTRODUCTION}

Polycyclic aromatic hydrocarbons are a widespread class of persistent organic pollutants and are known or suspect carcinogens ${ }^{1,2}$. From the list of priority pollutants, as defined by environmental protection agency, the concentrations of representative polycyclic aromatic hydrocarbons have been identified in terms of contamination levels for environmental studies $^{3,4}$. For this reason, it is necessary to get a clear view of the polycyclic aromatic hydrocarbon levels present in water samples, especially in drinking water ${ }^{5,6}$.

Many analytical techniques have been developed for the determination of polycyclic aromatic hydrocarbons in aqueous samples, such as liquid-liquid extraction ${ }^{7}$ and solid-phase extraction combined with a chromatographic system ${ }^{8,9}$. These conventional methods are tedious, time-consuming and require large amounts of solvent. Recently, new techniques, such as dispersive liquid phase microextraction are attracting attention, as they are simple, quick, solvent-efficient and economical $^{10}$.

The aim of the current work is to develop a reliable method for the dispersive liquid phase microextraction of six polycyclic aromatic hydrocarbons: fluoranthene (FLA), benzo(a)anthracene $(\mathrm{BaA})$, benzo(b)fluoranthene $(\mathrm{BbF})$, benzo(k)fluoranthene $(\mathrm{BkF})$, benzo(a)pyrene (BaP), benzo(g,h,i)perylene (BghiP). A number of variables and their interactions with one another, are believed to affect the extraction yields of the dispersive liquid phase microextraction. An optimization was performed to evaluate the optimal conditions for dispersive liquid phase microextraction. First, a Plackett-Burman design with two levels was used to devise the main parameters. The response surface method, with a central composite design, was then employed to determine the effects of various variables that can affect the extraction efficiency simultaneously.

\section{EXPERIMENTAL}

Single standard solutions, with concentrations of $100 \mathrm{mg} /$ $\mathrm{L}$ in $\mathrm{CH}_{2} \mathrm{Cl}_{2}$, were purchased from $\mathrm{J} \& \mathrm{~K}$ Chemical Ltd. (Beijing, China), including fluoranthene, benzo(a)anthracene, benzo(b)fluoranthene, benzo(k)fluoranthene, benzo(a)pyrene, benzo(g,h,i)perylene. Sodium chloride (Beijing chemical reagent factory, China) was of guaranteed reagent. Acetone, methanol, acetonitrile and perchloroethylene were of HPLC grade. Helium gas with purity of $99.999 \%$ was supplied by Jinan Deyang Special Gas Co. (Shandong, China).

Double-distilled water, which was boiled for $1 \mathrm{~h}$ in a large beaker to eliminate any polycyclic aromatic hydrocarbons, was used for the preparation of working polycyclic aromatic hydrocarbon solutions.

The standard solution was diluted in acetone and stored at $4{ }^{\circ} \mathrm{C}$ in the dark until use. All analyses were complete within $48 \mathrm{~h}$. 
A Shimadzu GCMS-QP 2010 gas chromatography system, coupled with a DB-5 capillary column $(30 \mathrm{~m} \times 0.25 \mathrm{~mm}$ i.d. and $0.25 \mu \mathrm{m}$ film thickness) and a mass spectrometer, was employed for the polycyclic aromatic hydrocarbons analysis. The oven temperature was held at $50^{\circ} \mathrm{C}$ for $2 \mathrm{~min}$, ramped to $200{ }^{\circ} \mathrm{C}$ at a rate of $19^{\circ} \mathrm{C} / \mathrm{min}$, to $240^{\circ} \mathrm{C}$ at $4.5^{\circ} \mathrm{C} / \mathrm{min}$, to $290^{\circ} \mathrm{C}$ at $2.5^{\circ} \mathrm{C} / \mathrm{min}$ and finally maintained at $290^{\circ} \mathrm{C}$ for $2 \mathrm{~min}$. Helium gas was supplied at $2 \mathrm{~mL} / \mathrm{min}$ as the carrier. The quadrupole, source and transfer line temperatures were maintained at 230 , 230 and $280{ }^{\circ} \mathrm{C}$, respectively. The electron ionization mass spectra were recorded at $70 \mathrm{eV}$ in full-scan mode over a mass range of 45-350 amu. All data were conducted on a GCMSQP2010 work station. The peaks were assigned using the NIST 98 mass spectrometry library and confirmed against the retention indexes of standards when available. Quantification was measured from the peak area normalization of target ions.

Dispersive liquid phase microextraction procedure: A $5 \mathrm{~mL}$ water sample, spiked with $5 \mathrm{ng} / \mathrm{L}$ aliquots of the six polycyclic aromatic hydrocarbons, was made up in a $10 \mathrm{~mL}$ glass vial. Methanol $(500 \mu \mathrm{L})$ was used as the disperser solvent, along with $50 \mu \mathrm{L}$ perchloroethylene as the extraction solvent, was rapidly added to the aqueous sample. This resulted in a cloudy mixture, which was gently shaken and then centrifuged for $3 \mathrm{~min}$ at $6000 \mathrm{rpm}$ until the disperser solvent had deposited at the bottom of the vial. The aqueous phase was removed and the residue was dissolved in $100 \mu \mathrm{L}$ methanol, from which $1 \mu \mathrm{L}$ was injected for analysis.

Water samples, including tap water, surface water and underground water, were collected for the validation of the method. Water samples were filtered through $0.45 \mu \mathrm{m}$ micropore membranes and stored at low temperature before use.

Experimental design and statistical analysis: The objective is to determine which factors influence the sensitivity of dispersive liquid phase microextraction. An experimental Plackett-Burman design, with two levels and a central composite design were used to evaluate the key factors for extraction. The extraction solvent type and volume, dispersive solvent type and volume, extraction time, $\mathrm{pH}$ and the effects of $\mathrm{NaCl}$ were all investigated in the experimental design.

The polynomial equation for the response variable, with respect to both discrete and continuous factors, was regressed using the software package Design Expert 7.1.0. A quadratic polynomial regression model was used to predict the response $^{11}$. The model proposed for the response $\mathrm{Y}$, is:

$$
\mathrm{Y}=\mathrm{b}_{0}+\sum \mathrm{b}_{\mathrm{i}} \mathrm{X}_{\mathrm{i}}+\sum \mathrm{b}_{\mathrm{ii}} \mathrm{X}^{2}{ }_{\mathrm{ii}}+\sum \mathrm{b}_{\mathrm{ij}} \mathrm{X}_{\mathrm{i}} \mathrm{X}_{\mathrm{j}}
$$

where, $\mathrm{Y}$ is the response variable; $\mathrm{b}_{0}$ is a constant; $\mathrm{b}_{\mathrm{i}}$ is a linear coefficient; $b_{i j}$ is a cross-product coefficient; and $b_{i i}$ is a quadratic coefficient. X reflects the coded levels of the independent variables.

The model fit was evaluated using the coefficients of determination $\left(\mathrm{R}^{2}\right)$ and analysis of variance (ANOVA). Threedimensional response surface curves were constructed to visualize the response. The optimized variable values can be obtained from the partial differentiation of the responses.

\section{RESULTS AND DISCUSSION}

Preliminary selection of extraction solvent: For the dispersive liquid phase microextraction procedure, the efficiency is dependent from the chemical nature of the target analytes. The correct extraction solvent should possess good chromatographic and extraction properties ${ }^{12}$. Perchloroethylene, toluene and dichloromethane were tested as the extraction solvent in dispersive liquid phase microextraction. Results revealed perchloroethylene to be excellent for the enrichment and isolation of all six polycyclic aromatic hydrocarbons. Therefore, perchloroethylene was selected as the extraction solvent for further experiments.

Effect of type of dispersive solvent: A prerequisite for dispersive solvent selection is that it must be miscible with the extraction solvent and the aqueous solution ${ }^{12}$. Three solvents, acetone, methanol and acetonitrile, were tested. Volumes of $0.5 \mathrm{~mL}$ were applied with perchloroethylene in the following tests. The results are summarized in Fig. 1. Methanol leads to better enrichment efficiencies for the six compounds compared to the other solvents. Methanol was therefore adopted as the dispersive solvent in subsequent tests.

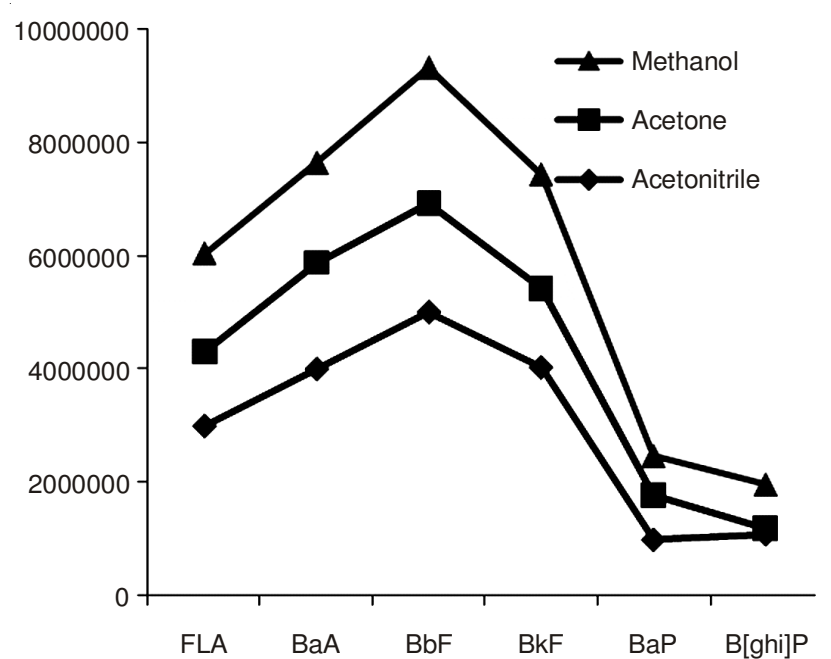

Fig. 1. Effects of different dispersive solvents on the enrichment efficiencies of the six polycyclic aromatic hydrocarbons

Plackett-Burman design with two levels: For the extraction, the dispersive liquid phase microextraction efficiency depends on numerous factors, meaning a sequential and thorough study would be complex and time consuming. An experimental Plackett-Burman design proved very useful for the initial steps of the optimization, as it allows the evaluation of multiple factors in a relatively simple and economical manner ${ }^{13}$. An experimental design was developed to screen for the main factors that influence the extraction efficiency.

Based on these preliminary studies and experiment results, the independent variables were established as follows (low/high value): volume of extraction solvent ( $\mu \mathrm{L})$ 40/80, volume of dispersive solvent $(\mu \mathrm{L}) 300 / 700$, extraction time (min) 2/8, pH (4/10) and $\mathrm{NaCl}$ concentration $(\mathrm{g} / \mathrm{mL})$ 0.0/0.2. The factors, their levels and the coded and uncoded values are shown in Table-1. Due to uncontrolled systematic errors, the ordering of the tests was randomized to avoid any skewness in the results.

The experiment design was carried out with 12 runs to screen for the factors that most significantly influence the responses of the six polycyclic aromatic hydrocarbons. The 
results of the analysis of variance from the Plackett-Burman design matrix and their responses are shown in Table-1.

\begin{tabular}{lcccc} 
TABLE-1 & & \\
\multicolumn{4}{c}{$\begin{array}{c}\text { LEVELS AND SYMBOLS FOR THE } \\
\text { INDEPENDENT VARIABLES }\end{array}$} \\
\cline { 2 - 4 } Variables & \multicolumn{2}{c}{ Levels } & \multirow{2}{*}{ T test } & Prob. \\
\hline Constant & & & 18.4 & $0.000^{\mathrm{a}}$ \\
A: volume of extraction solvent $(\mu \mathrm{L})$ & 40 & 80 & 3.21 & $0.018^{\mathrm{b}}$ \\
B: volume of dispersive solvent $(\mu \mathrm{L})$ & 300 & 700 & 2.76 & $0.033^{\mathrm{b}}$ \\
C: extraction time $(\mathrm{min})$ & 2 & 8 & -1.33 & 0.231 \\
D: $\mathrm{pH}$ & 4 & 10 & 4.31 & $0.005^{\mathrm{a}}$ \\
E: $\mathrm{NaCl}$ concentration $(\mathrm{g} / \mathrm{mL})$ & 0.0 & 0.2 & -1.03 & 0.342 \\
\hline
\end{tabular}

${ }^{\mathrm{a}}$ significant at $1 \%$ level; ${ }^{\mathrm{b}}$ significant at $5 \%$ level

The values from the T-tests less than 0.050 indicate that the independent variable has a significant effect on the response variable. In this case, the volume of the extraction solvent $(\mu \mathrm{L})$, volume of the dispersive solvent $(\mu \mathrm{L})$ and $\mathrm{pH}$ are all significant parameters. Conversely, values of greater than 0.050 mean the independent variables are not significant. But in this case extraction time (min) and $\mathrm{NaCl}$ concentration $(\mathrm{g} / \mathrm{mL})$ are significant. However, the addition of $\mathrm{NaCl}$ with agitation made the procedure more effective by allowing the transference of analytes from the matrix to the extractant. Thus, in the following experiments $0.1 \mathrm{~g} / \mathrm{mL} \mathrm{NaCl}$ (average concentration) was used.

Although in dispersive liquid phase microextraction, the mass transfer of the target compounds from the aqueous phase into extraction solvent is dependent on the extraction time, the cloudy solution forms rapidly and the surface area between the two phases is infinitely large. Therefore, equilibrium is achieved quickly and thus the extraction time is very short ${ }^{14}$. In our tests, a 5 min extraction time was selected.

Central composite design: Factorial designs are primarily used to extract the significant factors, but they can also be used to model and refine a process ${ }^{13}$. In this study, a threefactor three-level central composite design is required to identify the optimum set of experimental conditions. The total number of experiments needed $(\mathrm{N})$ for the central composite design is determined using the following equation:

$$
\mathrm{N}=2^{\mathrm{f}}+2 \mathrm{f}+\mathrm{N}_{0}
$$

where, $\mathrm{f}$ is the number of variables and $\mathrm{N}_{0}$ is the number of central points. Therefore, 20 experiments are needed for a central composite design with eight $\left(2^{3}\right)$ factorial points, six central points (star points). Six replicates are performed for the central points, which are used to estimate the experimental error (pure error). A coded value \pm 1 indicates the distance from the center of the design space to a factorial point, with the $\pm \alpha(|\alpha|>1)$ value, the mean of the distance from the center of the design space to the star point. The value of $\alpha$ was set to 1.68 based on the criterion for optimality, making all these points the same distance from the center ${ }^{13}$. The experiments were run in a random order to ensure that variability is observed in the response.

For the non-linearity of the MS response, a quadratic model was used to build a response surface method for the estimation of the response curvature in central composite design. The volume of the extraction solvent $(\mu \mathrm{L})$, volume of the dispersive solvent $(\mu \mathrm{L})$ and $\mathrm{pH}$ were used as significant parameters, but $\mathrm{NaCl}$ concentration $(\mathrm{mg} / \mathrm{L})$ and extraction time (min) were not included.

In the central composite design method, minimum or low levels (denoted as -1), central or medium levels (denoted as 0) and high or maximum levels (denoted as 1) are defined for each experimental factor (Table-2). The factor levels and the design matrix are shown in Table-2.

TABLE-2

THREE SELECTED FACTORS AND THEIR THREE LEVELS

\begin{tabular}{lccccc}
\hline \multirow{2}{*}{ Variable } & \multicolumn{5}{c}{ Variable levels } \\
\cline { 2 - 6 } & $-\alpha(-1.68)$ & -1 & 0 & +1 & $+\alpha(+1.68)$ \\
\hline $\begin{array}{l}\text { A: Volume of extraction } \\
\text { solvent }(\mu \mathrm{L})\end{array}$ & 26.40 & 40 & 60 & 80 & 93.60 \\
$\begin{array}{l}\text { B: Volume of dispersive } \\
\text { solvent }(\mu \mathrm{L})\end{array}$ & 164 & 300 & 500 & 700 & 836 \\
D: $\mathrm{pH}$ & 1.96 & 4 & 7 & 10 & 12.04 \\
\hline
\end{tabular}

The analysis of variables was employed to evaluate the significance of the model equation and the model terms are shown in Table-3. An F-value of 8.10 from the model indicates that it is significant. The model $p$-value lower than 0.05 (0.002), shows that the model is fit for use in the matrix. From the $p$ values for each model term, it can be concluded that the linear terms of A, B and D and the cross-product terms of $\mathrm{A} \times \mathrm{B}$, have a significant effect on the response (MS response).

The quality of the fit from the polynomial model equation is expressed by the coefficient of determination $\left(\mathrm{R}^{2}\right.$ and adjusted $\left.-\mathrm{R}^{2}\right) . \mathrm{R}^{2}$ is a measure of the variation around the mean, as explained by the model. The adjusted $-\mathrm{R}^{2}$ is adjusted for the number of terms in the mode ${ }^{13}$. The $\mathrm{R}^{2}$ and adjusted $-\mathrm{R}^{2}$ terms are also shown in Table-3. Values of 87.94 and $77.09 \%$ suggest that both the accuracy and general reliability of the polynomial model are adequate ${ }^{11}$.

\begin{tabular}{|c|c|c|c|c|c|}
\hline \multicolumn{6}{|c|}{$\begin{array}{c}\text { TABLE-3 } \\
\text { ANALYSIS OF VARIANCE FOR THE } \\
\text { FITTED QUADRATIC MODEL }\end{array}$} \\
\hline Regression & DF & $\begin{array}{l}\text { Sum of } \\
\text { squares }\end{array}$ & R-Square & $\begin{array}{c}\mathrm{F} \\
\text { Value }\end{array}$ & Prob. $>\mathrm{F}$ \\
\hline Model & 9 & $4.026 \times 10^{13}$ & $4.473 \times 10^{12}$ & 8.10 & $0.002^{\mathrm{b}}$ \\
\hline Linear & 3 & $3.629 \times 10^{13}$ & $1.210 \times 10^{13}$ & 21.92 & $0.000^{\mathrm{b}}$ \\
\hline Quadratic & 3 & $2.485 \times 10^{12}$ & $8.283 \times 10^{11}$ & 1.50 & 0.274 \\
\hline Cross-product & 3 & $1.480 \times 10^{12}$ & $4.934 \times 10^{11}$ & 0.89 & 0.478 \\
\hline Total & 19 & $4.578 \times 10^{13}$ & & & \\
\hline $\mathrm{R}^{2}=87.94 \%$ & \multicolumn{5}{|c|}{ Ajust-R ${ }^{2}=77.09 \%$} \\
\hline
\end{tabular}

A second-order polynomial equation was used to express the summed polycyclic aromatic hydrocarbon peak areas as a function of the independent variables as follows (using coded factors):

$$
\begin{gathered}
Y=10899302+1361006 \mathrm{~A}+458724 \mathrm{~B}+507078 \mathrm{D} \\
-40578 \mathrm{AB}-91071 \mathrm{BD}-109946 \mathrm{AD}-463357 \mathrm{~A}^{2} \\
-348988 \mathrm{~B}^{2}-342281 \mathrm{D}^{2}
\end{gathered}
$$

The regression equation comprises three main components, three two-factor interaction effects and three curvature effects, listed in Table-4. Eqn. (3), a mathematical correlation model, can be employed to predict and optimize the response, $\mathrm{Y}$, from the range of variables employed in the experiment. A 
variable is claimed to have greater influence on the response if its coefficient is relatively larger. A variable with a positive coefficient has an enhancing effect towards the response, whereas a negative coefficient has the opposite effect ${ }^{11}$. As inferred from eqn. (3), which includes the coefficient for each effect, the volume of extraction solvent (A), the volume of dispersive solvent (B) and $\mathrm{pH}$ (D) all have positive coefficients $(\mathrm{A},+1361006, \mathrm{~B}+458724, \mathrm{D}+507078)$.

\begin{tabular}{ccccc}
\multicolumn{5}{c}{ TABLE-4 } \\
\multicolumn{5}{c}{$\begin{array}{c}\text { RESULTS FROM THE REGRESSION ANALYSIS FOR A } \\
\text { FULL SECOND-ORDER POLYNOMIAL MODEL }\end{array}$} \\
\hline Variable & DF & Sum of Squares & F Value & Prob.>F \\
\hline Model & 9 & $4.026 \times 10^{13}$ & 8.10 & $0.0015^{\mathrm{a}}$ \\
$\mathrm{A}$ & 1 & $2.898 \times 10^{13}$ & 52.50 & $<0.0001^{\mathrm{b}}$ \\
$\mathrm{B}$ & 1 & $3.292 \times 10^{12}$ & 5.96 & $0.0347^{\mathrm{a}}$ \\
$\mathrm{D}$ & 1 & $4.023 \times 10^{12}$ & 7.29 & $0.0223^{\mathrm{a}}$ \\
$\mathrm{A}^{*} \mathrm{~B}$ & 1 & $1.1317 \times 10^{12}$ & 2.39 & $0.0434^{\mathrm{a}}$ \\
$\mathrm{B}^{*} \mathrm{D}$ & 1 & $6.635 \times 10^{10}$ & 0.12 & 0.7360 \\
$\mathrm{~A}^{*} \mathrm{D}$ & 1 & $9.670 \times 10^{10}$ & 0.18 & 06844 \\
$\mathrm{~A}^{2}$ & 1 & $2.125 \times 10^{12}$ & 3.85 & 0.0782 \\
$\mathrm{~B}^{2}$ & 1 & $1.205 \times 10^{12}$ & 2.18 & 0.1703 \\
$\mathrm{D}^{2}$ & 1 & $1.159 \times 10^{12}$ & 2.10 & 0.1779 \\
\hline${ }^{\mathrm{a}}$ significant at $1 \%$ level; ${ }^{\mathrm{b}}$ significant at $5 \%$ level
\end{tabular}

A normal probability plot of the residual shows an approximately linear distribution, meaning the errors are evenly distributed (Fig. 2). This supports a least-square fit.

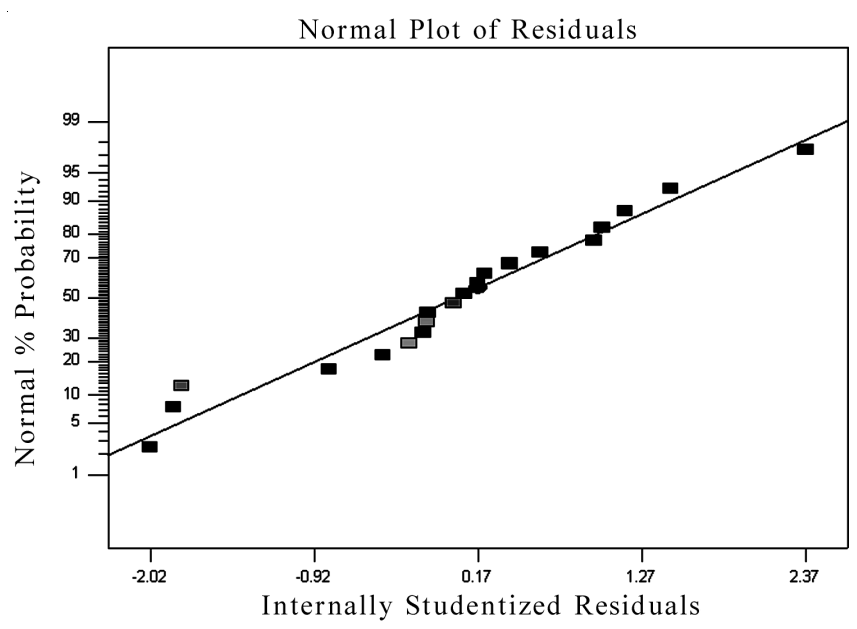

Fig. 2 Normal probability plot of residual for the response

The interactions between two different factors can be interpreted with ease from interaction diagrams (Fig. 3). At points where two lines are not parallel, the effects of one factor depend on the level of the other factor. Interactions were observed between the volume of extraction solvent and the volume of dispersive solvent (Fig. 3a), but not between the volumes of either extraction or dispersive solvent and $\mathrm{pH}$ (Fig. $3 \mathrm{~b}$ and $3 \mathrm{c}$, respectively). ANOVA results (Table-4) confirm that the cross-product term $\mathrm{A} \times \mathrm{B}$ is significant at a $5 \%$ level.

To express the effects of any parameter on the response in a clearer way, three-dimensional response surface curves were created as a function of the interactions between any two variables, by holding the other variable at its central level (0) (Fig. 4). The plot shape allows one to estimate the signifi- cance of the mutual interactions between the independent variables. These plots are a visual representation of the relationships between the response and each experimental factor. All three plots exhibit a similar relationship for the effects of each variable.
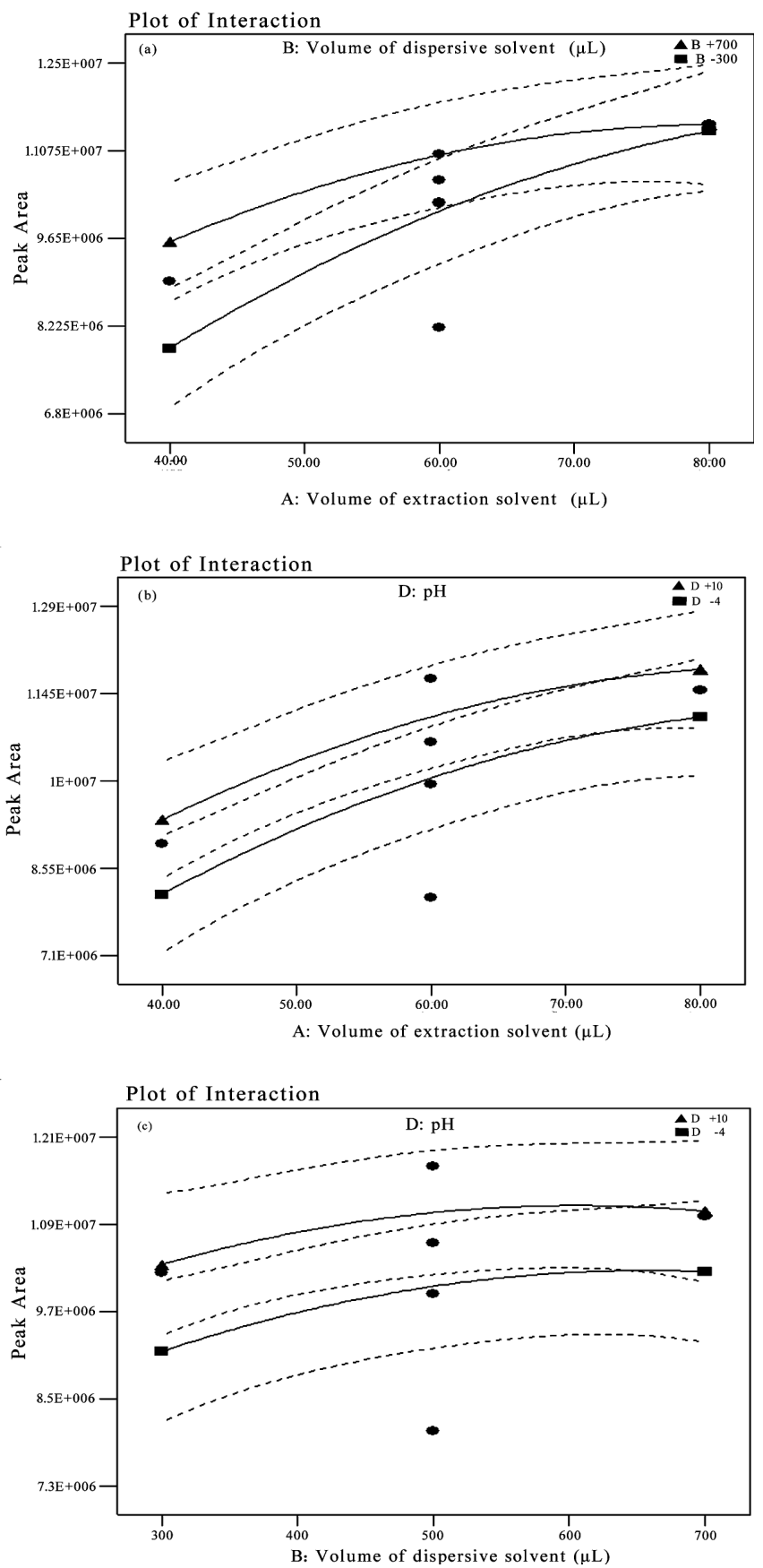

Fig. 3. Two-factor interactions and their effects on the efficiency: (a) volume of extraction solvent and volume of dispersive solvent; (b) volume of extraction solvent and $\mathrm{pH}$; and (c) volume of dispersive solvent and $\mathrm{pH}$

The response surface curve for the predicted response, as a function of the volume of extraction solvent and the volume of dispersive solvent (Fig. 4), shows the response has a good correlation with the volume of extraction solvent, volume of dispersive solvent and pH. From Fig. 3a, we can see that initially, with increases in both extraction and dispersive solvent 
volume, the response also increases. When volume of extraction solvent goes beyond $60 \mu \mathrm{L}$ and the volume of dispersive solvent reaches $500 \mu \mathrm{L}$, the change in response remains stable. Due to the addition of extraction and dispersive solvent, a cloudy solution is formed and the surface area between the phases is infinitely large. Upon increasing the extraction and dispersive solvent volumes over 60 and $500 \mu \mathrm{L}$, respectively, there is a large probability for the combination of extraction droplets to form a larger droplet. This decreases the surface area between the two phases and increases the solubility of the six polycyclic aromatic hydrocarbons in water. With low volumes of dispersive solvent, the cloudy state is not well established, so the extraction yields are low. However, with higher volumes of dispersive solvent, the equilibrium is achieved ${ }^{14}$.
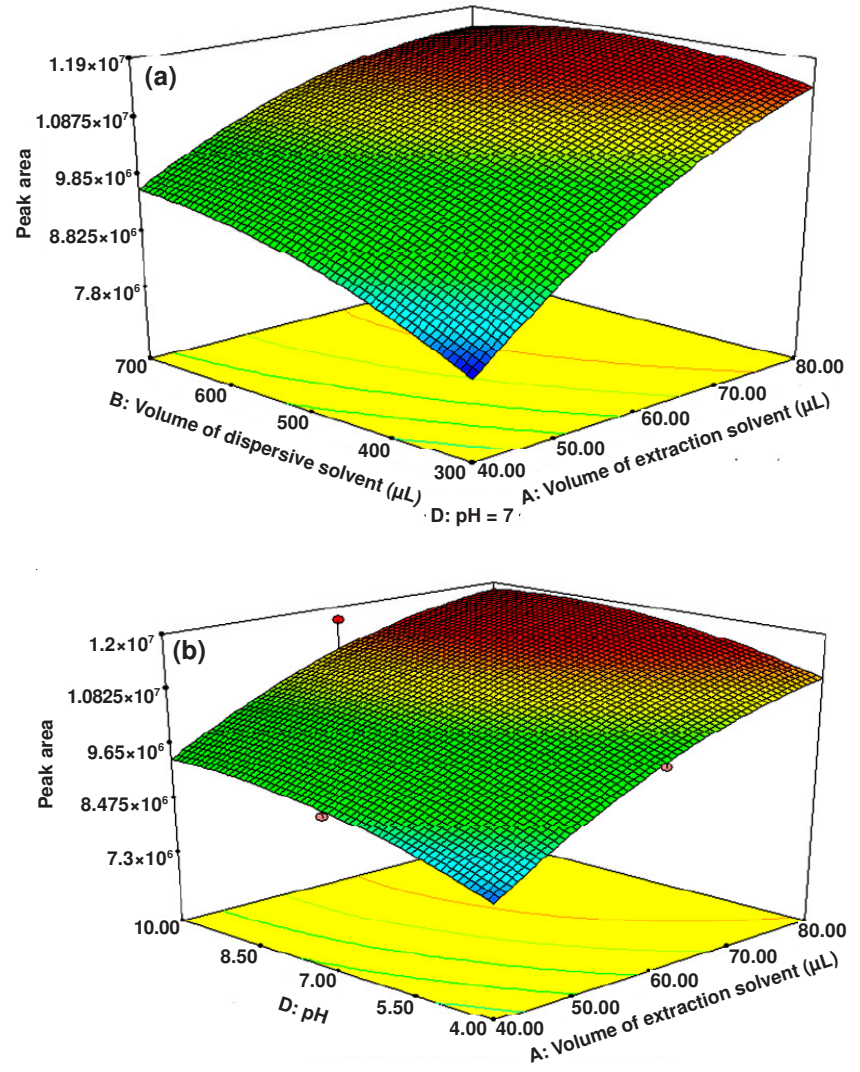

B: Volume of dispersive solvent $=500 \mu \mathrm{L}$

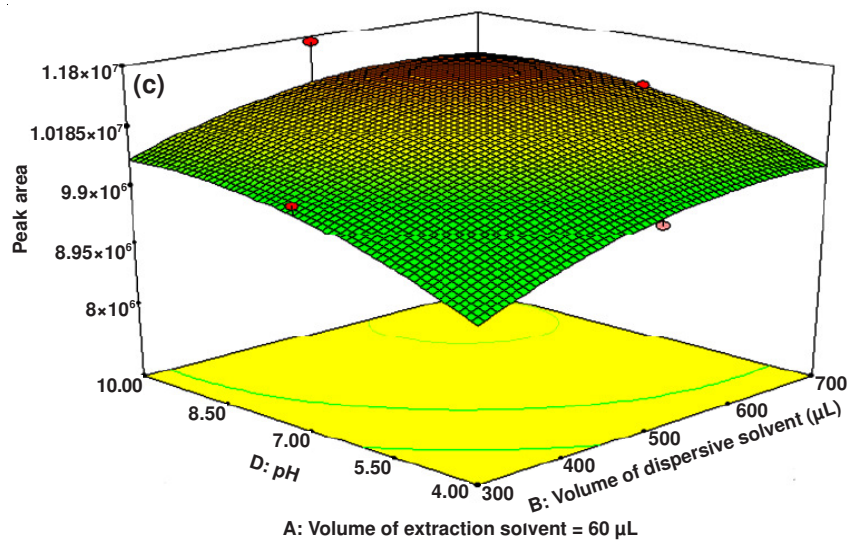

Fig. 4. Response surface curves, showing the predicted responses as an interaction function between two variables, achieved by holding the other at its central level: (a) volume of extraction solvent and volume of dispersive solvent; (b) volume of extraction and $\mathrm{pH}$; (c) volume of dispersive solvent and $\mathrm{pH}$
Fig. $4 \mathrm{~b}$ showed that the increasing of $\mathrm{pH}$ improves the enrichment factor. When the $\mathrm{pH}$ increases over 7 , the response remains plateaus. There is a negative effect on the response, as illustrated in Fig. 4c. The $\mathrm{pH}$ changes may result in the protonation/deprotonation of the extraction solvent. Thus, the solubilities of the six polycyclic aromatic hydrocarbons in water are enhanced significantly and the levels of target in sedimented extract are reduced ${ }^{14}$.

Therefore, in subsequent experiments, $60 \mu \mathrm{L}$ extraction solvent, $500 \mu \mathrm{L}$ of dispersive solvent and a $\mathrm{pH}$ of 7 were deemed sufficient for the extraction.

Evaluation for the method performance: The response surface method adjusted optimum conditions of $60 \mu \mathrm{L}$ extraction solvent (methanol), $500 \mu \mathrm{L}$ dispersive solvent (perchloroethylene) and neutral $\mathrm{pH}(\mathrm{pH} 7)$ were combined with the recommended $\mathrm{NaCl}$ concentration of $0.1 \mathrm{~g} / \mathrm{mL}$ and an extraction time of $5 \mathrm{~min}$. These conditions were used to measure the analytical characteristics for the proposed dispersive liquid phase microextraction-GC-MS method (Table-5). The linearity of the calibration ranged from 1-100 ng/L for the six analytes. The coefficients of determination $\left(\mathrm{R}^{2}\right)$ ranged from 0.932 to 0.995 . The reproducibility was investigated over six replicate experiments under the optimized conditions, using an aqueous standard polycyclic aromatic hydrocarbon solution of $2 \mathrm{ng} / \mathrm{L}$. The relative standard deviations (RSDs \%) for the polycyclic aromatic hydrocarbons ranged from 9.0 to $11.3 \%$. The limits of detection (LODs), based on a signal-to-noise ratio (S/N) of three, ranged from $0.52-1.67 \mathrm{ng} / \mathrm{L}$. In comparison with environmental protection agency (environmental protection agency) method 8100, the LODs obtained in this study are lower than those reported by the environmental protection agency for all six analytes.

TABLE-5

QUANTITATIVE RESULTS FROM THE DLPME-GC-MS ANALYSIS OF PAHs, USING THE ADJUSTED OPTIMIZED CONDITIONS FROM THE RSM

\begin{tabular}{cccccc}
\hline Comp. & $\begin{array}{c}\text { Linear range } \\
(\mathrm{ng} / \mathrm{L})\end{array}$ & $\mathrm{R}^{2}$ & $\begin{array}{c}\mathrm{RSD}(\%) \\
(\mathrm{n}=6)\end{array}$ & $\begin{array}{c}\mathrm{LOD} \\
(\mathrm{ng} / \mathrm{L})\end{array}$ & $\begin{array}{c}\text { EPA method } \\
8100 \mathrm{LOD}(\mathrm{ng} / \mathrm{L})\end{array}$ \\
\hline $\mathrm{FLT}$ & $1-100$ & 0.957 & 9.6 & 1.67 & 43.0 \\
$\mathrm{BaA}$ & $1-100$ & 0.962 & 11.3 & 0.85 & 4.0 \\
$\mathrm{BbF}$ & $1-100$ & 0.995 & 9.0 & 1.55 & 3.1 \\
$\mathrm{BkF}$ & $1-100$ & 0.990 & 10.3 & 0.52 & 2.5 \\
$\mathrm{BaP}$ & $1-100$ & 0.932 & 10.2 & 0.87 & 4.0 \\
$\mathrm{BghiP}$ & $1-100$ & 0.954 & 9.2 & 0.64 & 2.3 \\
\hline
\end{tabular}

Real water sample analysis: Using the proposed optimum conditions, the dispersive liquid phase microextraction was applied to the analysis tap water and underground water. Tap water was collected from a laboratory. Underground water came from a well, which is relatively clean and approved for consumption without pretreatment. The results show that the underground water is free from polycyclic aromatic hydrocarbon contamination. There were no polycyclic aromatic hydrocarbons detected in the under-ground water. There was no $\mathrm{BaA}$ or BghiP in the tap water, but FLT, BbF, BkF and $\mathrm{BaP}$ were all detected (Table-6). However, the individual and combined concentrations for all the polycyclic aromatic hydrocarbons in the tap water are all below $200 \mathrm{ng} / \mathrm{L}$, which fulfills world health organization guidelines. The recoveries 
of FLT, BaA BbF, BkF, BaP and BghiP ranged from 83.5$116.3 \%$ in the tap water and underground water (Table-6). This demonstrates that both tap and under-ground water matrices have little effect on the dispersive liquid phase microextraction.

TABLE-6

DETERMINATION OF PAHS IN TAP WATER AND UNDERGROUND WATER USING THE OPTIMIZED DISPERSIVE LIQUID PHASE MICROEXTRACTION

\begin{tabular}{|c|c|c|c|c|c|}
\hline \multirow[b]{2}{*}{ Comp. } & \multicolumn{2}{|c|}{ Tap water } & \multicolumn{2}{|c|}{ Underground water } & \multirow{2}{*}{$\begin{array}{c}\text { WHO } \\
\text { guidelines } \\
(\mathrm{ng} / \mathrm{L})\end{array}$} \\
\hline & $\begin{array}{l}\text { Found } \\
\text { (ng/L) }\end{array}$ & $\begin{array}{c}\text { Recovery } \\
(\%)\end{array}$ & $\begin{array}{l}\text { Found } \\
\text { (ng/L) }\end{array}$ & $\begin{array}{c}\text { Recovery } \\
(\%)\end{array}$ & \\
\hline FLT & 8.0 & 87.6 & ND & 90.3 & 200 \\
\hline $\mathrm{BaA}$ & ND & 110.3 & ND & 108 & 200 \\
\hline $\mathrm{BbF}$ & 12.2 & 94.7 & ND & 110.6 & 200 \\
\hline $\mathrm{BkF}$ & 3.3 & 98.1 & ND & 96.4 & 200 \\
\hline $\mathrm{BaP}$ & 1.4 & 114.2 & ND & 116.3 & 200 \\
\hline BghiP & ND & 109.7 & ND & 83.5 & 200 \\
\hline Total & 24.7 & & & & \\
\hline
\end{tabular}

\section{Conclusion}

In this study, the extraction of polycyclic aromatic hydrocarbons from drinking water for analysis by dispersive liquid phase microextraction, coupled to capillary column gas chromatography mass spectrometry, was optimized. A secondorder response surface method was used to optimize the independent variables for the absorption of the polycyclic aromatic hydrocarbons. The extraction solvent volume, dispersive solvent volume and $\mathrm{pH}$ were found to be important variables, which upon increasing, improved the extraction efficiency. ANOVA of central composite design was used to reveal the quadratic and interaction terms, revealing the relationships between the factors and their influence on efficiency. These statistical experiments allowed us to determine the best experimental conditions, using the minimum number of trials. This optimized extraction with dispersive liquid phase microextraction is a useful tool for the analysis of polycyclic aromatic hydrocarbons in drinking water.

\section{ACKNOWLEDGEMENTS}

This work was financially supported by the National Natural Science Foundation of China (Project 51178159), the Program for New Century Excellent Talents in University of China (Grant No. NCET-08-0877) and the Program for Science and Technology Development of Shandong Province, China (Grant No. 2009GG 10006015).

\section{REFERENCES}

1. Q.L. Li, X.Q. Xu and F.S. Lee, Sci. China Ser B: Chem., 49, 481 (2006).

2. R. Rodil, M. Schellin and P. Popp, J. Chromatogr. A, 1163, 288 (2007).

3. M.T. Pena, M.C. Casais, M.C. Mejuto and R. Cela, J. Chromatogr. A, 1216, 6356 (2009).

4. H. Xu, Z.Q. Ding, L.L. Lv, D.D. Song and Y.Q. Feng, Anal. Chim. Acta, 636(1), 28 (2009).

5. Y.X. Shao and X.Q. Xu, Elect. Technol. Civil Engg. (ICETCE), 4, 4290 (2011).

6. M.I. Leong, C.C. Chang, M.R. Fuh and S.D. Huang, J. Chromatogr. A, 1217, 5455 (2010).

7. D.H. Lin, Y.Y. Tu and L.Z. Zhu, Food Chem. Toxicol., 43, 41 (2005).

8. S.L. Fan, L.X. Zhao and J.M. Lin, Talanta, 72, 1618 (2007).

9. M.S. García-Falcón, B. Cancho-Grande and J. Simal-Gándara, Food Chem., 90, 643 (2005).

10. X.D. Wang, L.Y. Fu, G.H. Wei, J. Hu, X.N. Zhao, X.J. Liu and Y.Y. Li, J. Sep. Sci., 31, 2932 (2008).

11. S.L.C. Ferreira, W.N.L.D. Santos and C.M. Quintella, Talanta, 63, 1061 (2004).

12. S. Berijani, Y. Assadi, M. Anbia, H.M.R. Milani and E. Aghaee, J. Chromatogr. A, 1123, 1 (2006).

13. H. Sereshti, M. Karimi and S. Samadi, J. Chromatogr. A, 1216, 198 (2009).

14. R.S. Zhao, X. Wang, J. Sun, S.S. Wang, J.P. Yuan and X.K. Wang, Anal. Bioanal. Chem., 397, 1627 (2010). 